\title{
Quarterly Orevieu \\ Cytomegalovirus infection in patients with Inflammatory Bowel Disease: A major player or an innocent bystander?
}

\author{
Devendra C Desai
}

ABSTRACT

Department of Gastroenterology, P D Hinduja Hospital, Veer Savarkar Marg, Mahim, Mumbai-400016.

Correspondence: Devendra C Desai

Email:_devendracdesai@gmail.com

Cytomegalovirus (CMV) infection was described in patients with Inflammatory Bowel Disease (IBD) about 50 years ago. CMV infection may mimic a relapse of IBD. The role of CMV in IBD remains controversial. Of 23 studies during 1999 to 2015,16 of 23 studies during 1999 to 2015, 16 studies found that CMV had an an unfavorable impact on the disease status where as there was no impact on disease status in 7 studies. Recent literature suggests a way to recognize patients who need treatment for CMV. Patients older than 30 years, those with steroids and immunosuppressant resistance and those needing increase in dose of immunosuppressant drugs need to be investigated for CMV colitis. Histological examination of colonic mucosa (Hematoxylin and eosin, and immunohistochemistry), colonic mucosal biopsy PCR DNA amplification assay and blood PCR for viremia are the diagnostic tests advised for the diagnosis of CMV colitis and CMV infection.

KEYWORDS: Cytomegalovirus; inflammatory bowel disease.

\section{Introduction}

With the advent of immunosuppressants, there is increasing risk of superimposed infection in patients with Inflammatory Bowel Disease (IBD). Superimposed infective episodes not only worsen the symptoms, they may also mimic a relapse of IBD and are often difficult to differentiate.

Powell and Levine independently reported Cytomegalovirus (CMV) infection in IBD patients in the 1960's. ${ }^{1,2}$ However, later studies did not find an association between CMV and IBD. This review will attempt to delineate the role of CMV in the pathogenesis of IBD, as either an innocent bystander or a major player.

\section{Factsheet}

1. Although almost $70 \%$ of human beings are likely to be infected with $\mathrm{CMV}$, the majority, being immunocompetent, are unlikely to manifest. ${ }^{3}$ CMV can cause infection in immunocompromised individuals. $^{4}$ 
2. The inflamed mucosa in IBD patients is more susceptible to infection by CMV. CMV is unlikely to invade endoscopically normal mucosa.,

3. CMV infection occurs more often in patients with ulcerative colitis than in patients with Crohn's disease. This may be explained by the pathogenesis of $\mathrm{CD}$, which is a Th1 type of inflammatory process, with high expression of Interferon $-\gamma$. IFN - $\gamma$ suppresses CMV reactivation. ${ }^{7}$

4. CMV infection may rarely involve ileo-anal pouch. ${ }^{8}$

5. Histological prevalence of CMV in new onset ulcerative colitis is $4.5 \%$, in exacerbation of IBD 8 to $10.4 \%$ (histology and colonic tissue PCR), acute colitis admissions $16.6 \%$ and in severe ulcerative colitis $13.8 \%$. $^{9-14}$

6. We need to differentiate between diagnostic tests for CMV infection and diagnostic test for CMV colitis.

The diagnostic tests for $C M V$ infection include. ${ }^{15}$

\section{Serological tests}

IgG and IgM. Multiple reports suggest that IgM antibody to $\mathrm{CMV}$ does not appear in patients with CMV colitis. . $^{5,16}$

\section{Antigenemia assay}

pp65 antigen in peripheral neutrophils- This is semiquantitative test. Although it has good sensitivity and specificity, it does not differentiate between latent infection and active disease.

\section{PCR DNA amplification in blood}

This test also does not differentiate between latent and active infection in IBD. There is correlation between PCR and detection of colonic CMV. ${ }^{17}$ Some investigators have stratified patients according to copies per mg of tissue.

\section{PCR assay in stool}

Athough this assay is performed on stool sample, it is not commonly used.

\section{Histology}

Histological diagnosis with hematoxylin and eosin ( $\mathrm{H} \& \mathrm{E})$ staining shows presence of enlarged cell and intranuclear inclusions. It has a specificity of $92-100 \%$ but sensitivity of only $10-87 \%$. Immunohistochemistry (IHC) is the gold standard for diagnosis and has a higher sensitivity of $78-93 \%{ }^{18,19}$ McCurdy et al. recommend a flexible sigmoidoscopy with 11 biopsies in UC and colonoscopy with 16 biopsies in $\mathrm{CD}$ to obtain $80 \%$ chance of a single positive biopsy. ${ }^{20}$

\section{PCR DNA amplification assay in colon mucosa}

Colonic mucosal biopsy tissue PCR DNA has recently been found to be useful in a French study. When done in flare up of UC or refractory disease, more than $250 \mathrm{CMV}$ copies/mg had sensitivity of $100 \%$ and specificity of $66 \%$ and was predictive of resistance to steroids and advanced treatment. This cut off has also been used in other studies to treat the CMV colitis. ${ }^{5}$

\section{Endoscopy}

No findings on endoscopy are diagnostic of CMV infection. Punched out ulcers, longitudinal ulcers and geographic ulcers are common in CMV colitis. However, ulcers are related more to the disease than to CMV. ${ }^{16,21}$

Who should be tested for CMV and which diagnostic tests should be used?

In the setting of severe disease, disease refractory to cortico steroids and in patients on immunosuppressant drugs, testing for CMV should be done. This should include histological examination of colonic biopsies and immunohistochemistry and/or blood PCR, which has been found to have good correlation with histology. The 2014 revised European Crohn's and colitis organization guidelines (on management of opportunistic infection in IBD) suggest histology with immunohistochemistry and colonic tissue PCR for the diagnosis of CMV colitis. ${ }^{22}$ These guidelines also suggest that CMV should be excluded before increasing immunosuppression. 


\section{CMV - a major player or an innocent bystander?}

Several studies have looked at the association between CMV and IBD with diverse results. Pillet et $\mathrm{al}^{23}$ summarized the studies and found various factors that could have contributed to the varied results: Primary CMV infection had been clubbed together with reactivation, the studies had taken UC and CD together even though they had vastly different rates of CMV infection and the studies had used different diagnostic tests. There were 23 studies from 1999 to 2015, including 1208 patients with UC and 178 patients with $\mathrm{CD}$. The population with $\mathrm{UC}$ was divergent- UC with no mention of severity, active disease, varying degree of severity of UC, refractory UC and patient with colectomy. 16 studies found CMV to have an unfavorable impact on disease status whereas 7 found no impact. The unfavorable outcome was variably defined: more steroid dependence, requirement of colectomy, avoidance of colectomy by anti viral treatment and the requirement for hospitalization. Thus, it can be concluded that CMV reactivation is a marker of poor prognosis in patients with IBD and is associated with unfavorable outcomes.

\section{Approach to treatment in an individual patient}

A recent article by Abdul-Baki Heitham et al outlined a treatment plan based on stratification of patients into 3 categories. Some patients have colonic CMV infection associated with viremia. This is suggestive of systemic CMV infection and warrants treatment for CMV infection. Patients without systemic viremia but features of colonic involvement in the form of punched out ulcers need CMV treatment followed by treatment for IBD in the form of medications or operative therapy. However, some patients neither have viremia nor deep colonic ulcers, and only show evidence of CMV on histology or immunohistochemistry. In this group, it is likely that they have inflammation due to activity of ulcerative colitis and CMV is likely to be innocent bystander. ${ }^{24}$

McCurdy et al. found that patients with medically refractory disease, patients treated with immunosuppressant (not tumor necrosis factor (TNF) antagonist) and age older than 30 years were independently associated with CMV disease. The use of TNF antagonist was not a significant factor for the development of CMV disease..$^{25}$

Pellet et al. suggest a quantification of CMV density in colonic tissue in patients with refractory ulcerative colitis (defined by steroid resistance or immunosuppressive treatment or anti-TNF drugs) more than 30 years of age. They divide patients into three categories - patients with no CMV in colonic tissue, patients with low-grade density (10 to 250 copies/mg tissue and less than $4 \mathrm{CMV}$ inclusions in biopsy by immunohistochemistry), and patients with high-grade density (more than 250 copies $/ \mathrm{mg}$ of tissue or more than 4 inclusions in biopsy by immunohistochemistry). Patients with low-grade density CMV associated with stigmata of severe disease (need for hospitalization and Lichtiger score more than 10) and patients with high-grade density should be treated for CMV infection. ${ }^{23}$

What about steroids and/or immunosuppressants when CMV infection is present and needs treatment?

In the three groups described by Abdul-Baki et al., the first group of patients, who have systemic CMV infections in addition to colonic CMV infections, are usually moribund. In these patients, immunosuppressants should be stopped and steroid should be reduced. After treating CMV infection, if the IBD remains active, the patients should be treated with biologic therapy or referred for surgery. Tumor necrosis factor (TNF) antagonists do not reactivate latent $\mathrm{CMV}$ in CMV seropositive patients with IBD. $^{25-27}$

\section{Treatment of CMV colitis}

Ganciclovir intravenously in a dose of $5 \mathrm{mg} / \mathrm{kg}$ twice a day for 2 to 3 weeks is the first line therapy. After 2 to 3 days, IV therapy can be switched to oral valganciclovir, which has excellent oral absorption. Resistance to Ganciclovir should be suspected if there is no response to treatment. Side effects of Ganciclovirinclude myelosuppression, rash, nausea, vomiting and headache. Intravenous Foscarnet is the second choice but is not easily available. 
In summary, although there is controversy regarding the role of CMV in $\mathrm{IBD}$, most studies suggest an unfavorable outcome associated with CMV infection. Patients older than 30 years, those with steroids and immunosuppressants resistance and those needing increase in dose of immunosuppressant drugs need to be investigated for CMV colitis. The recommended diagnostic tests for CMV include histological examination of colonic mucosa ( $\mathrm{H} \& \mathrm{E}$ and immunohistochemistry), colonic mucosal biopsy PCR DNA amplification assay and blood PCR. Patients with CMV viremia and CMV colitis should be treated (immunosuppressant should be stopped and steroids should be reduced). Patients with steroid refractory disease and endoscopic ulcers should also be treated. After the treatment of CMV infection, treatment of IBD should be tailored according to the needs of the individual.

\section{References}

1. Powell RD, Warner NE, Levine RS, Kirsner JB. Cytomegalic inclusion disease and ulcerative colitis: report of a case in a young adult. Am J Med. 1961;30:334-40.

2. Levine RS, Warner NE, Johnson CF. Cytomegalic Inclusion Disease in the gastro-intestinal Tract of Adults. Ann Surg. 1964;159:37-48.

3. Hanley PJ, Bollard CM. Controlling cytomegalovirus: helping the immune system take the lead. Viruses. 2014;6:2242-2258.

4. You DM, Johnson MD. Cytomegalovirus infection and the gastrointestinal tract. Curr Gastroenterol Rep. 2012;14:334-342.

5. Roblin X, Pillet S, Oussalah A, Berthelot P, Del Tedesco E, Phelip JM et al. Cytomegalovirus load in inflamed intestinal tissue is predictive of resistance to immunosuppressive therapy in ulcerative colitis. Am $J$ Gastroenterol. 2011;106:2001-2008.

6. Zidar N, Ferkolj I, Tepeš K, Štabuc B, Kojc N, Uršič T, et al. Diagnosing cytomegalovirus in patients with inflammatory bowel disease-by immunohistochemistry or polymerase chain reaction? Virchows Arch. 2015;466:533-539.

7. Nakase H, Yoshino T, Honzawa Y, Chiba T. Low prevalence of CMV infection in patients with Crohn's disease in comparison with ulcerative colitis: effect of different immune response on prevalence of CMV infection. Dig Dis Sci. 2010;55:1498-1499.
8. McCurdy JD, Loftus EV, Tremaine WJ, Smyrk TC, Bruining DH, Pardi DS et al. Cytomegalovirus Infection of the Ileoanal Pouch: Clinical Characteristics and Outcomes. Inflamm Bowel Dis. 2013;19:2394-2399.

9. Sager K, Alam S, Bond A, Chinnappan L, Probert CS. Cytomegalovirus and Inflammatory Bowel Disease. Aliment Pharmacol Ther. 2015;41:725-733.

10. Kim JJ, Simpson N, Klipfel N, Debose R, Barr N, Laine L. Cytomegalovirus infection in patients with active inflammatory bowel disease. Dig Dis Sci. 2010;55:105965.

11. Leveque N, Brixi-Benmansour H, Reig T, Renois F, Talmud $\mathrm{D}$, Brodard $\mathrm{V}$, et al. Low frequency of cytomegalo virus infection during exacerbations of inflammatory bowel diseases. J Med Virol. 2010;82:1694-700.

12. Kim YS, Kim YH, Kim JS, et al. Cytomegalovirus infection in patients with new onset ulcerative colitis: a prospective study. Hepatogastroenterology. 2012;59:1098-101.

13. Criscuoli V, Casa A, Orlando A, Pecoraro G, Oliva L, Traina M, et al. Severe acute colitis associated with CMV: a prevalence study. Dig Liver Dis. 2004;36:818-20.

14. Kambham N, Vij R, Cartwright CA, Longacre $\mathrm{T}$. Cytomegalovirus infection in steroid-refractory ulcerative colitis: a casecontrol study. Am J Surg Pathol. 2004;2013:365-73.

15. Garrido E, Carrera E, Manzano R, Lopez-Sanroman A. Clinical significance of cytomegalovirus infection in patients with inflammatory bowel disease. World $J$ Gastroenterol. 2013;19:17-25.

16. Iida T, Ikeya K, Watanabe F,Abe J, Maruyama Y, Ohata A, et al. Looking for endoscopic features of cytomegalovirus colitis: a study of 187 patients with active ulcerative colitis, positive and negative for cytomegalovirus. Inflamm Bowel Dis. 2013;19:1156-63.

17. Yoshino T, Nakase H, Ueno S, Uza N, Inoue S, Mikami S, et al. Usefulness of quantitative real-time PCR assay for early detection of cytomegalovirus infectionin patients with ulcerative colitis refractory to immunosuppressivetherapies. Inflamm Bowel Dis. 2007;13:1516-1521.

18. Beaugerie L, Cywiner-Golenzer C, Monfort L, Girard PM,Carbonnel F, Ngô Y, et al. Definition and diagnosis of cytomegalovirus colitis in patients infected by human immunodeficiencyvirus. J Acquir Immune Defic Syndr Hum Retrovirol. 1997;14: 423-429.

19. Kandiel A, Lashner B. Cytomegalovirus colitis complicatinginflammatory bowel disease. $\mathrm{Am} J$ Gastroenterol. 2006;101:2857-2865. 
20. McCurdy J D, Enders, FT, Jones, A, Killian JM. Loftus EV Jr, Bruining, DH, et al. Detection of Cytomegalovirus in Patients with Inflammatory Bowel Disease: Where to Biopsy and How Many Biopsies? Inflamm Bowel Dis. 2015;21:2833-2838.

21. Suzuki H, Kato J, Kuriyama M, Hiraoka S, Kuwaki K, Yamamoto K. Specific endoscopic features of ulcerative colitis complicated by cytomegalovirus infection. World $J$ Gastroenterol. 2010;16:1245-51.

22. Rahier JF, F. Magro F, Abreu C, Armuzzi A, Ben-Horin $\mathrm{S}$, Chowers $\mathrm{Y}$ et al. Second European evidence-based consensuson the prevention, diagnosis and management of opportunistic infections in inflammatorybowel disease. $J$ Crohns Colitis. 2014;8:443-468.

23. Pillet S, Pozzetto B, Roblin X. Cytomegalovirus and ulcerative colitis: place of viral therapy. World $J$
Gastroenterol. 2016;22:2030-2045.

24. Abdul-Baki H, Greer JB, Binion DG. Kermanshahi TR, Brand MH, Williams ED, et al. IBD LIVE Case Series-Case 5: The Many Faces of Cytomegalovirus in Inflammatory Bowel Disease. Inflamm Bowel Dis. 2016;22:2245-54.

25. D'Ovidio V, Vernia P, Gentile G, et al. Cytomegalovirus infection in inflammatory bowel disease patients undergoing anti-TNF alpha therapy. J ClinVirol. 2008;43:180-183.

26. Lavagna A, Bergallo M, Daperno M, et al. Infliximab and the risk of latent viruses reactivation in active Crohn's disease. Inflamm Bowel Dis. 2007;13:896-902.

27. McCurdy JD, Jones A, Enders FT, Jill M. Killian JT, Loftus Jr EV, et al. A Model for Identifying Cytomegalovirus in Patients With Inflammatory Bowel Disease. Clinical Gastroenterology and Hepatology. 2015;13:131-137. 